\title{
Finite element analysis of overlay incorporating stress absorbing membrane interlayers against reflective cracking
}

\author{
O. M. Ogundipe $\cdot$ N. H. Thom $\cdot$ A. C. Collop
}

Received: 22 November 2013/Revised: 26 February 2014/Accepted: 5 March 2014/Published online: 21 March 2014

(C) The Author(s) 2014. This article is published with open access at Springerlink.com

\begin{abstract}
A wheel tracking test was modelled to gain better understanding of the deflection and stress-strain distribution in an overlaid cracked pavements with and without membrane interlayer (SAMI). For this purpose, commercial finite element software Abaqus 6.7-1 was used. Two different models were considered, one incorporating stress absorbing membrane interlayers (SAMIs) and the other without SAMI. In the study, full bond condition was assumed for the boundaries between the layers, and a linear elastic model was used for the analysis. The results show that introduction of SAMI caused greater deflection of the pavement. It is found that although with SAMIs, low stiffness is required, a very low stiffness may yield undesirable results. The results show that the introduction of SAMIs results in high strain concentration around the crack region, whilst the strain in the overlay is smaller than the values predicted in the models without SAMIs.
\end{abstract}

Keywords Overlay $\cdot$ Interlayers $\cdot$ Crack $\cdot$ Strain $\cdot$ Stress

\section{Introduction}

Most of the pavement projects around the world today are rehabilitations of existing road pavements (rigid and

O. M. Ogundipe $(\square)$

Civil Engineering Department, Ekiti State University, Ado-Ekiti,

Nigeria

e-mail: momide2002@yahoo.com

N. H. Thom

NTEC, University of Nottingham, Nottingham, UK

A. C. Collop

Faculty of Technology, De-Montfort University, Leicester, UK flexible). The common method adopted (overlaying) has been plagued with the problem of reflective cracking. Engineers have battled the problem for years introducing various measures, but the fight is far from being won. Cleveland et al. [1] defined reflective cracking as the propagation of cracks from the movement of the underlying pavement or base course into and through the new overlay as a result of loadinduced and/or temperature induced stresses. Palacios et al. [2] reported that cracks propagate to new overlays due to vertical movement of the underlying pavement layer which may be due to traffic loading, frost heave and consolidation of the subgrade soils and/or the horizontal movement of the pavement upper layers due to temperature changes.

This study assesses the contribution of some stress absorbing membrane interlayers (SAMIs) on overlaid pavement performance in delaying the offset of reflective cracking using finite element analysis. SAMIs are designed to dissipate energy by deforming horizontally or vertically; therefore, allowing the movement (vertical/horizontal) of the underlying pavement layers without causing large tensile stresses in the asphalt overlay. As observed by Kim and Buttlar [3], the primary benefit of a soft interlayer is to reduce the longitudinal stresses in the overlay caused by wheel load and/or thermal cycling.

In this study, a wheel tracking test was modelled to gain better understanding of the deflection and stress-strain distribution in overlaid cracked pavements with and without SAMIs. In the modelling, the propagation of the crack was not considered; therefore, the modelling only gives the deflection and stress-strain distribution before crack initiation. The materials stiffnesses were determined for the finite element analysis. The modelling was done with a commercial finite element programme Abaqus 6.7-1 [4]. Abaqus/Standard was implemented in Abaqus/CAE to generate the models for the study. 


\section{Finite element formulation}

Although asphalt behaves more like a viscoelastic material, for simplicity, it was considered appropriate to use a linear elastic model for the analysis. As observed by Sousa et al. [5], two major factors are of particular interest in the mechanical analysis of hot-mix asphalt: the material characterisation method and its accuracy in reflecting the material resistance to loading and the accuracy of mechanistic models to predict the pavement performance. Nesnas and Nun [6] in their study of top-down reflection cracking found that the linear elastic model was able to give explanation for the field observation that the reflection crack can initiate at the surface and propagate downwards. Portillo [7] used the linear elastic software EVERSTRESS and the finite element software Abaqus to predict the pavement responses using linear elastic and visco-elastic models. He found that the results from the linear elastic analyses (EVERSTRESS) were similar to the measured pavement response values, except for vertical pressures, whilst the results from the visco-elastic finite element model (FEM) were much smaller than the measured values. His results for the linear elastic model in Abaqus were similar to the ones from EVERSTRESS. He stated that the problem with the visco-elastic modelling might be the prony series parameters used for the analysis. Bekheet et al. [8] modelled the in situ shear strength testing of asphalt concrete pavements using linear elastic model in Abaqus and found that the correlation between the field results and each of the FEMs and the mathematical models was very high (with correlation factor of $86 \%$ ). They stated that it implied that the linear elastic approximation for the asphalt pavement behaviour might be an acceptable approximation. Therefore, the linear elastic model was considered appropriate for this study.

\subsection{Wheel tracking test}

The wheel tracking test is capable of generating the maximum shear stress and the maximum bending stress that occur when a moving wheel is either slightly offset from or directly over a crack, respectively. This produces mode I and mode II cracking. The wheel tracking machine was located in a temperature controlled room, which allows the effect of temperature on SAMI performance to be studied. The wheel tracker consists of a reciprocating table which moves forwards and backwards with a frequency of $0.8 \mathrm{~Hz}$ under the loaded wheel with a travel length of $225 \mathrm{~mm}$. The solid tyre fitted to the wheel has an outside diameter of $200 \mathrm{~mm}$ and width of $50 \mathrm{~mm}$. The test replicates what happens when a cracked pavement overlaid with and without interlayers (SAMIs) is trafficked.
The specimens were manufactured in three layers for the wheel cracking test, the base layer (simulating the existing pavement) with a $10 \mathrm{~mm}$ notch (simulating the crack), which was made of $10 \mathrm{~mm}$ asphalt concrete with $10 / 20$ penetration grade bitumen, and the middle layer (where present) was SAMI. The SAMIs considered in the modelling are proprietary SAMIs A and B and sand asphalt, and the top layer (overlay) was also made of $10 \mathrm{~mm}$ asphalt concrete but with 40/60 penetration grade bitumen. The control specimens were made in two layers: the top layer and the base layer. The specimen was placed on a $10 \mathrm{~mm}$ rubber mat in a steel mould. It was loaded after clamping it at the top and side at both ends to simulate pavement continuity.

As mentioned earlier, a linear elastic material model was adopted for the specimens. Therefore, the material properties required for the finite element modelling are the elastic modulus, $E$ and Poisson's ratio, $\mu$. The elastic modulus (stiffness) was determined using the indirect tensile stiffness modulus (ITSM) test. The stiffness was used directly because the temperatures are the same, and wheel loading rate is close to the ITSM loading rate. The properties of each of the layers at 10,20 and $30^{\circ} \mathrm{C}$ are as shown in Table 1. The parameters considered in the modelling include the overlay and SAMI thicknesses and the test temperature. The test temperature was considered using the material properties obtained in the laboratory tests at 10,20 and $30^{\circ} \mathrm{C}$ for the modelling.

\subsection{Model geometry}

The models (with and without SAMIs) were developed to investigate the performance of the SAMIs. The model length and width are 404 and $50 \mathrm{~mm}$, respectively. The overall thicknesses considered in the model are 110, 120 and $130 \mathrm{~mm}$. The combinations investigated are shown in Table 2. They were investigated at 10,20 and $30^{\circ} \mathrm{C}$.

A 3-dimensional analysis was carried out. The load was placed across the entire beam width of $50 \mathrm{~mm}$. The layers were simulated using an 8-node linear brick, reduced integration element (C3D8R) - the first order isoparametric element. The C3D8R elements have only one integration point, thereby, reducing the computational time without any great effect on the result accuracy. Reduced integration usually means that an integration scheme one order less than the full scheme is used to integrate the element internal forces and stiffness [4]. Typical 3-dimensional structural models for the wheel tacking test for specimens with $10 \mathrm{~mm}$ SAMIs and $60 \mathrm{~mm}$ overlay and control model with $70 \mathrm{~mm}$ overlay are shown in Fig. 1. Cracks in an existing pavement have been modelled using different approaches by researchers. Wu and Harvey [9] modelled a crack with empty spaces in the underlying layer; Minhoto 
Table 1 Layer properties

\begin{tabular}{|c|c|c|c|}
\hline \multirow[t]{2}{*}{ Materials } & \multicolumn{3}{|l|}{ Properties } \\
\hline & $E(\mathrm{MPa}),(\mu)$ at $10^{\circ} \mathrm{C}$ & $E(\mathrm{MPa}),(\mu)$ at $20^{\circ} \mathrm{C}$ & $E(\mathrm{MPa}),(\mu)$ at $30^{\circ} \mathrm{C}$ \\
\hline $10 \mathrm{~mm}$ AC (40/60) & $10,035(0.25)$ & $3,899(0.35)$ & $1,098(0.45)$ \\
\hline 10 mm AC (10/20) & $15,435(0.25)$ & $9,591(0.35)$ & $5,008(0.45)$ \\
\hline Proprietary SAMI A & $8,548(0.25)$ & $2,725(0.35)$ & $635(0.45)$ \\
\hline Proprietary SAMI B & $7,564(0.25)$ & $2,444(0.35)$ & $510(0.45)$ \\
\hline Sand asphalt & $635(0.25)$ & $209(0.35)$ & $118(0.45)$ \\
\hline Crack & & $1(0.35)$ & \\
\hline Rubber & & $6.45(0.49)$ & \\
\hline Steel & & $209,000(0.3)$ & \\
\hline
\end{tabular}

$E$ stiffness, $\mu$ Poisson's ratio

Table 2 Combinations investigated

\begin{tabular}{|c|c|c|c|c|c|c|c|}
\hline Layer thickness (mm) & $\mathrm{C} 1$ & $\mathrm{C} 2$ & C3 & $\mathrm{C} 4$ & C5 (control) & C6 (control) & C7 (control) \\
\hline Overlay & 40 & 40 & 60 & 60 & 60 & 70 & 80 \\
\hline SAMI & 20 & 30 & 10 & 20 & - & - & - \\
\hline Base & 30 & 30 & 30 & 30 & 30 & 30 & 30 \\
\hline Rubber & 10 & 10 & 10 & 10 & 10 & 10 & 10 \\
\hline Steel & 10 & 10 & 10 & 10 & 10 & 10 & 10 \\
\hline Total & 110 & 120 & 120 & 130 & 110 & 120 & 130 \\
\hline
\end{tabular}

$C$ combination

et al. [10] modelled cracks using elements without stiffness in their study of reflective cracking behaviour for traffic and temperature effects. Pais and Pereira [11] modelled cracks as a void with a negligible stiffness of $1 \mathrm{MPa}$. Also, Dave et al. [12] and Baek and Al-Qadi [13] modelled cracks using a cohesive zone model. In this study, the crack was modelled by assigning a low material stiffness to the elements (see Table 1).

The mesh density that is appropriate for the study was determined by checking different mesh densities. A density that saves time without affecting the accuracy of the results was selected. Therefore, the specimens with $20 \mathrm{~mm}$ SAMI and $40 \mathrm{~mm}$ overlay and control specimens with $60 \mathrm{~mm}$ overlay were modelled with 31,200 elements, whilst the specimens with $30 \mathrm{~mm}$ SAMI and $40 \mathrm{~mm}$ overlay, $10 \mathrm{~mm}$ SAMI and $60 \mathrm{~mm}$ overlay and control specimens with $70 \mathrm{~mm}$ overlay were modelled with 33,600 elements. Lastly, the specimens with $20 \mathrm{~mm} \mathrm{SAMI}$ and $60 \mathrm{~mm}$ overlay and control specimens with $80 \mathrm{~mm}$ overlay were modelled with 37,200 elements.

\subsection{Material properties}

In the ITSM, a load pulse is applied to the vertical diameter of the specimen positioned centrally between the upper and the lower platens, and the resultant peak transient deformation along the horizontal diameter was measured. The method uses cylindrical specimens cored from the field or slabs in the laboratory. In this case, the cores were cut from slab produced in the laboratory. These cores are usually 150 or $100 \mathrm{~mm}$ in diameter and has thickness between 30 and $80 \mathrm{~mm}$. Input parameters include target horizontal deformation, load rise time, Poisson's ratio, test temperature, specimen thickness and diameter. The test was carried out in accordance with DD 213: 1993 [14]. For this study, the test conditions were as follows: sample diameter: $100 \mathrm{~mm}$; sample thickness: $40 \pm 4 \mathrm{~mm}$; Target rise time: $124 \pm 4 \mathrm{~ms}$ and Mean horizontal deformation: $5 \pm 2 \mu \mathrm{m}$.

The results of the ITSM test (Table 1) show that the stiffness of the mixtures decreased with increasing temperature. Also, all the SAMI mixtures have lower stiffness than the overlay mixture $(10 \mathrm{~mm}$ asphalt concrete with $40 / 60$ penetration grade bitumen). The sand asphalt with very low stiffness was chosen to evaluate an extreme case, different from the two proprietary SAMIs A and B.

The rubber mat was used in the wheel tracking test to simulate an elastic foundation and induce bending stress. The stiffness of the rubber mat was determined by conducting a compression test using the MAND axial testing machine. The stress rate was $100 \mathrm{~N} / \mathrm{s}$, and the diameter of load bearing plates (top and bottom) (mm) was $150 \mathrm{~mm}$. The rubber stiffness was calculated as $6.45 \mathrm{MPa}$. 


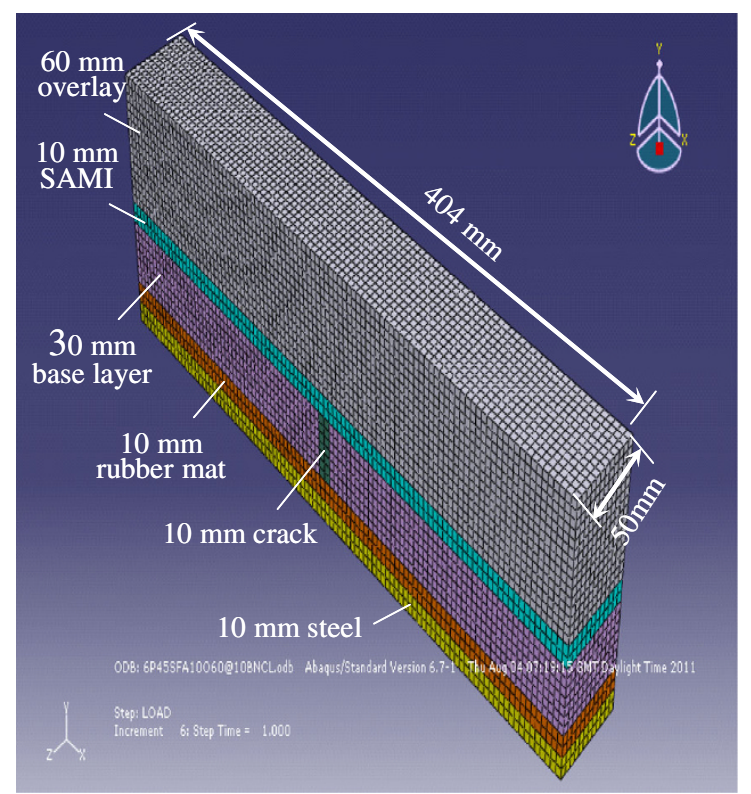

(a)

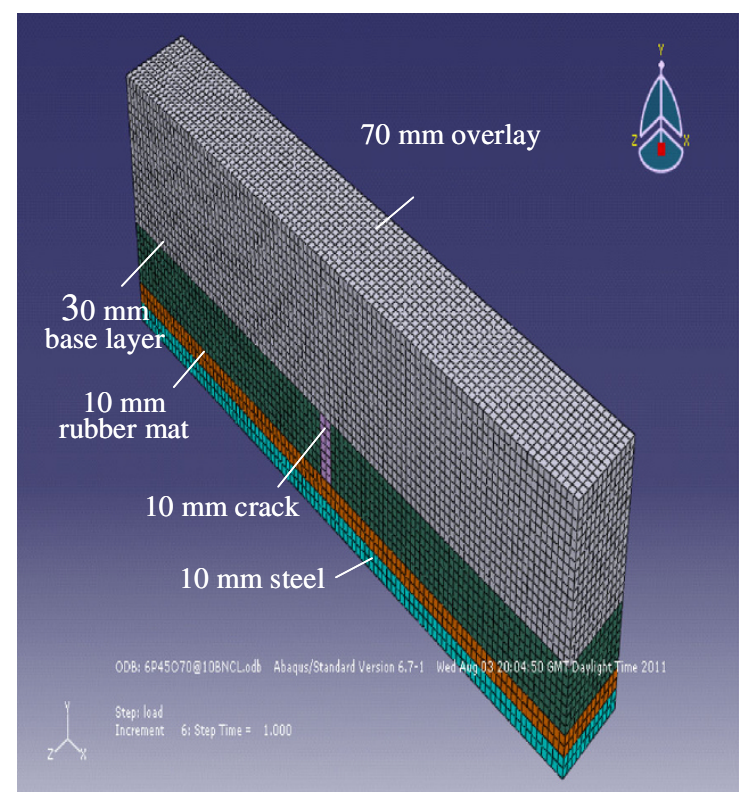

(b)

Fig. 1 Typical models. a $10 \mathrm{~mm}$ SAMI and $60 \mathrm{~mm}$ overlay. b $70 \mathrm{~mm}$ overlay (control)

Table 3 Models reference

\begin{tabular}{ll}
\hline Name & Reference \\
\hline $60 \mathrm{~mm}$ overlay (control) & O60 \\
20-mm-thick sand asphalt with $40 \mathrm{~mm}$ overlay & SA20O40 \\
20-mm-thick proprietary SAMI A with $40 \mathrm{~mm}$ overlay & PA20O40 \\
20-mm-thick proprietary SAMI B with $40 \mathrm{~mm}$ overlay & PB20O40 \\
$70 \mathrm{~mm}$ overlay (control) & O70 \\
$30-\mathrm{mm}$-thick sand asphalt with $40 \mathrm{~mm}$ overlay & SA30O40 \\
30-mm-thick proprietary SAMI A with $40 \mathrm{~mm}$ overlay & PA30O40 \\
$30-\mathrm{mm}$-thick proprietary SAMI B with $40 \mathrm{~mm}$ overlay & PB30O40 \\
10-mm-thick sand asphalt with $60 \mathrm{~mm}$ overlay & SA10O60 \\
10-mm-thick proprietary SAMI A with $60 \mathrm{~mm}$ overlay & PA10O60 \\
10-mm-thick proprietary SAMI B with $60 \mathrm{~mm}$ overlay & PB10O60 \\
80 mm overlay (control) & O80 \\
20-mm-thick sand asphalt with $60 \mathrm{~mm}$ overlay & SA20O60 \\
20-mm-thick proprietary SAMI A with $60 \mathrm{~mm}$ overlay & PA20O60 \\
20-mm-thick proprietary SAMI B with $60 \mathrm{~mm}$ overlay & PB20O60 \\
\hline
\end{tabular}

\subsection{Loading and boundary conditions and contact} modelling

A distributed load of $2.4 \mathrm{kN}(1.1 \mathrm{MPa})$ was chosen for the modelling. The load was applied on the whole width $(50 \mathrm{~mm})$ of the beam over a length of $45 \mathrm{~mm}$. It was applied at two different locations on the overlay. The first location was $90 \mathrm{~mm}$ away from the centre of the crack, termed 'edge load', and the second location was applied directly above the simulated crack, termed 'centre load'. Only one side of the model was considered because of

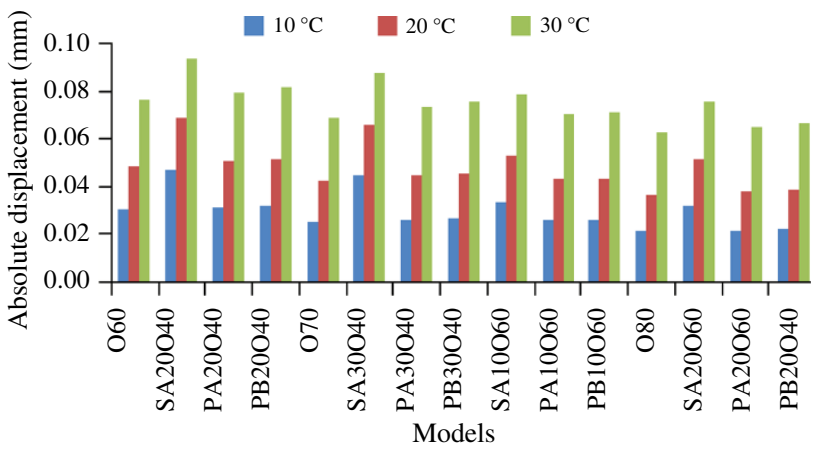

Fig. 2 Absolute displacement of models

symmetry. Fixed boundary condition was applied to the steel base and the ends of the models. The fixed boundary condition (encastre) constrains the model movement, i.e. the displacement and rotation in $x, y$ and $z$ directions. Full bond condition (compatibility of stresses and strains) was assumed for contact modelling.

\section{Results and analysis}

The models' references are shown in Table 3. The results for the overlay were taken $20 \mathrm{~mm}$ from the bottom of the overlay. For the models with 10, 20 and $30 \mathrm{~mm}$ SAMIs, $20 \mathrm{~mm}$ from the bottom of the overlay is equivalent to 30 , 40 and $50 \mathrm{~mm}$ from the bottom of the overlay in their respective control specimens. Readings for the crack region were taken $4 \mathrm{~mm}$ above the crack top. The predicted strain 


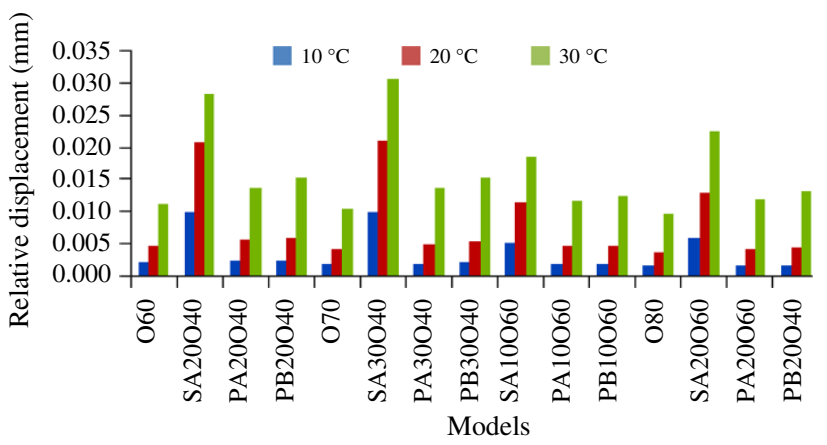

Fig. 3 Relative displacement of models

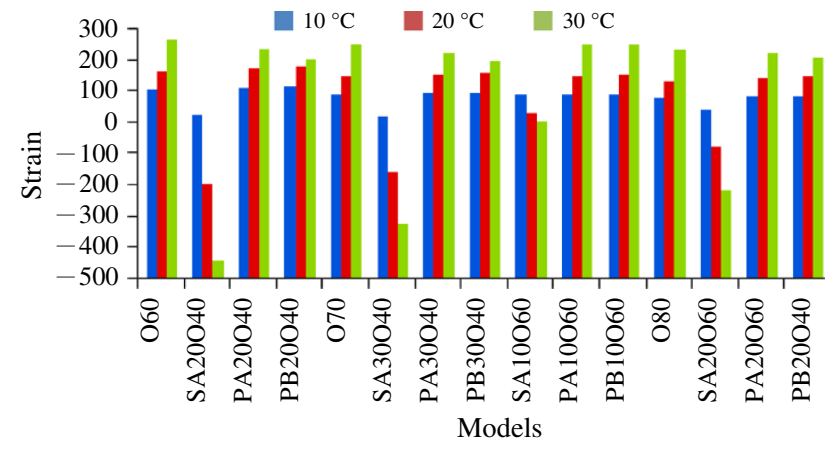

Fig. 4 Strain in the crack region

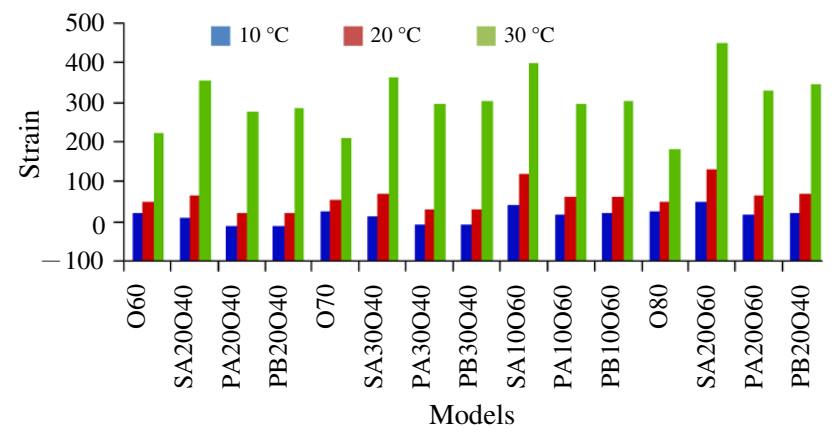

Fig. 5 Strain in the overlay

was obtained as the difference in values when the load was placed at the centre directly above the crack top and at the edge ( $90 \mathrm{~mm}$ from the centre). The results of the stress were predicted when the load was placed at the centre.

\subsection{Displacement}

The predicted absolute and relative displacements at 10,20 and $30{ }^{\circ} \mathrm{C}$ are shown in Figs. 2 and 3. It can be seen from the figures that there are more absolute and relative displacements in the specimens with SAMIs than the control sections without SAMI. Also, the models with lower SAMI thickness have less displacement. The results show that the

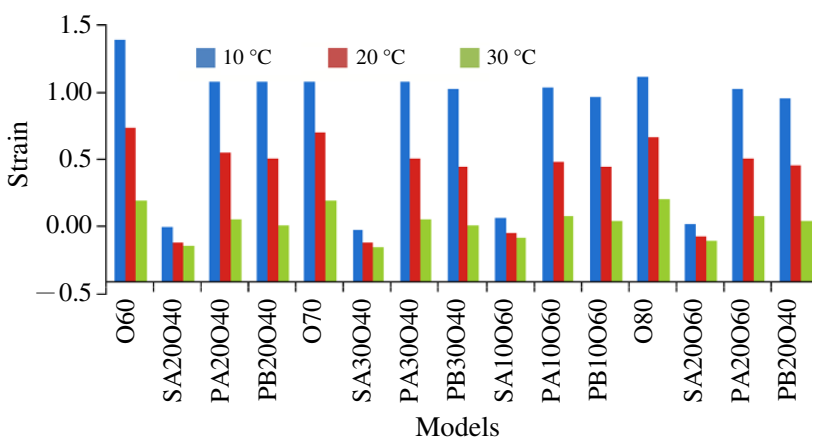

Fig. 6 Longitudinal stress in the crack region at 10,20 and $30^{\circ} \mathrm{C}$

absolute and relative displacements of the specimens increase with temperature. The reason for the increased displacements in the specimens with SAMIs is because of the introduction of a layer with lower stiffness between the overlay and the existing pavement.

\subsection{Strain}

The strains in the crack region ( $4 \mathrm{~mm}$ above the crack top) and in the overlay at 10,20 and $30^{\circ} \mathrm{C}$ are shown in Figs. 4 and 5. Figure 4 shows that the strains around the crack region in the specimens with SAMIs are greater than the strains in the models with no SAMIs. High strain concentration occurs around the crack region of the models with SAMIs. This is thought to be because of the increased displacement that accompanied the introduction of SAMIs of low stiffness and the ability of the SAMIs to deform in response to the movement of the underlying cracked layer. Also, the figure indicates that at $30{ }^{\circ} \mathrm{C}$ less strain was predicted in the crack region of the models with SAMIs than those without SAMI with the exception of the specimens with sand asphalt, which were in compression.

Figure 5 shows the strain predicted at the bottom of the overlay for both control specimens and those with SAMIs. The figure indicates that the strains at the bottom of the overlay are lower in the specimens with SAMIs than those without SAMIs, except the specimens with sand asphalt as SAMI, which have greater strain than the control. However, at $30^{\circ} \mathrm{C}$, the results are mixed. This is probably due to the high load magnitude and temperature. Whilst high strain concentration exists around the crack region in the models with SAMIs, the lower strains in the overlay indicate that the SAMIs are able to isolate the overlay from the strain concentration. Moreover, since greater strains were predicted in the overlay of models with sand asphalt as SAMIs, it shows that they might not be able to retard reflective cracking. The predicted strains increase with increasing temperature. This indicates that performance reduces as temperature increases. 


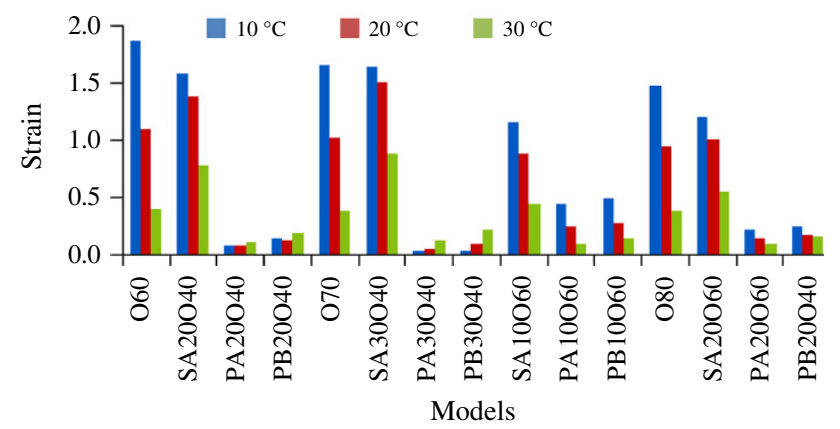

Fig. 7 Longitudinal stress in the overlay at 10,20 and $30{ }^{\circ} \mathrm{C}$

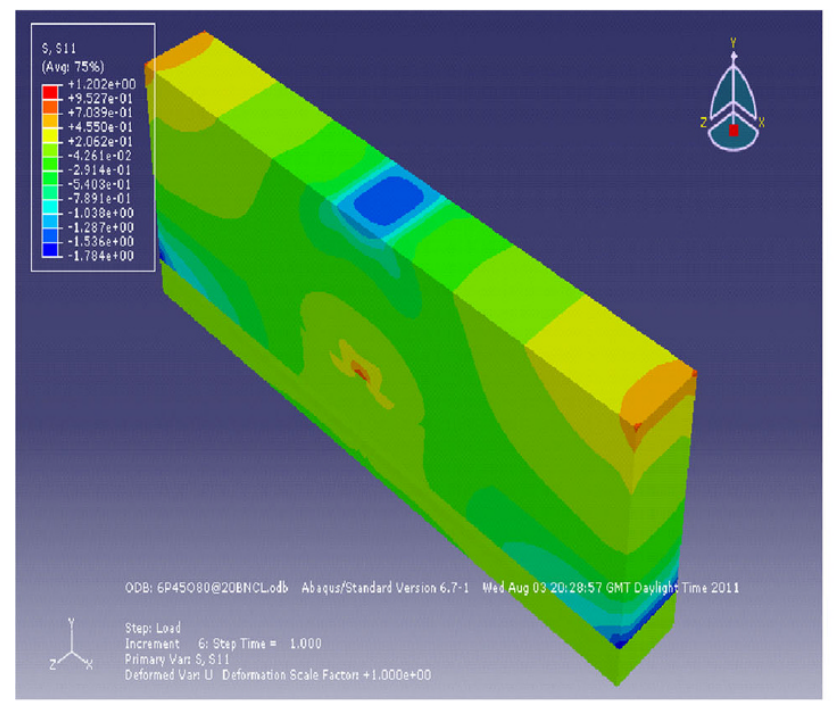

(a)

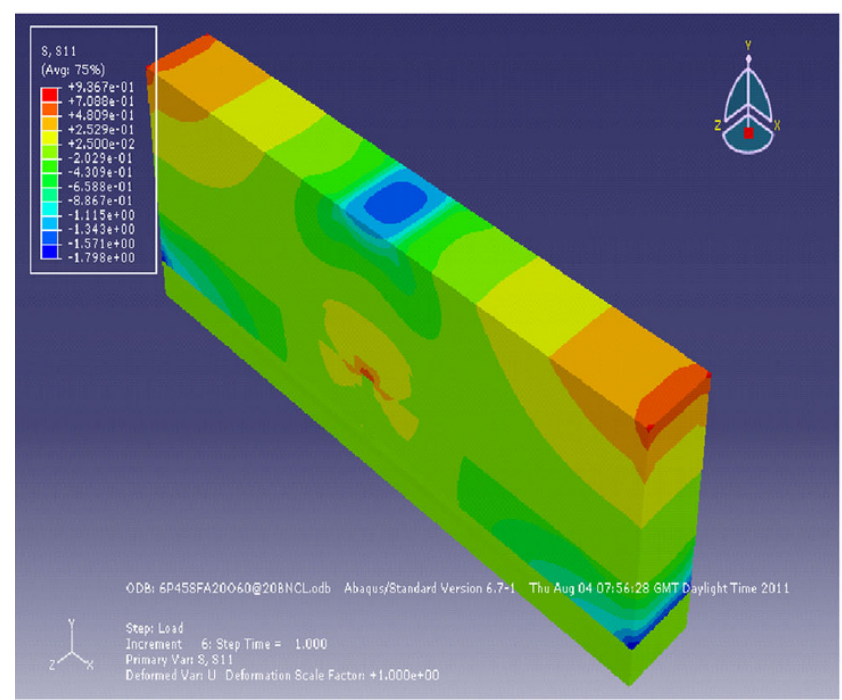

(c)

\subsection{Stress}

Figure 6 shows the tensile stresses predicted in the crack region of the models with SAMIs are smaller than those without SAMI. The models having sand asphalt as SAMI are in compression.

Also, Fig. 7 shows that the tensile stresses predicted in the overlay of the models with proprietary SAMIs A and B are smaller than those predicted in the overlay of their respective control specimens, whilst for the models with sand asphalt as SAMI, the tensile stresses predicted in the

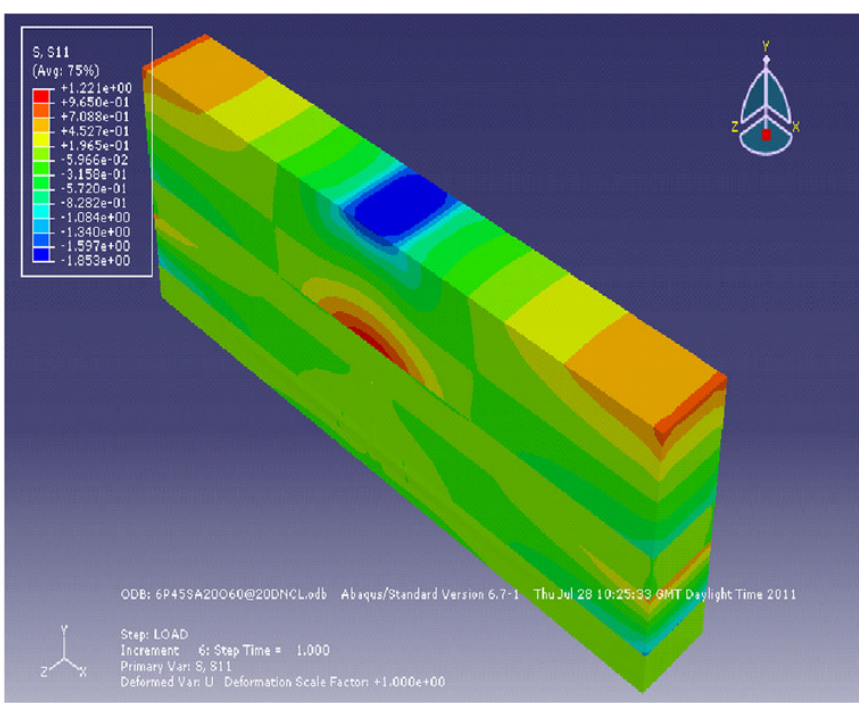

(b)

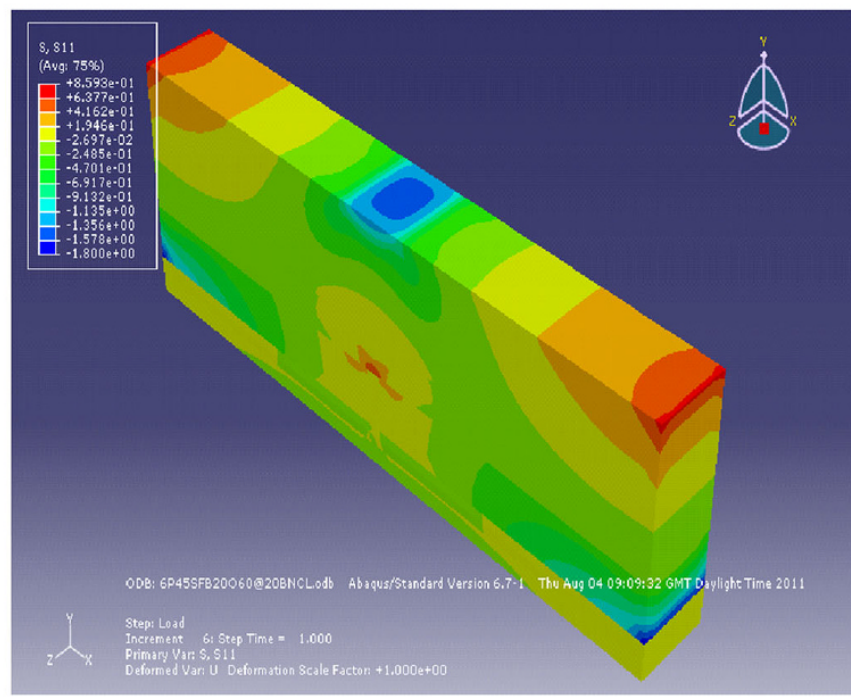

(d)

Fig. 8 Longitudinal stress contour plots. a $80 \mathrm{~mm}$ overlay (control). b $20 \mathrm{~mm}$ sand asphalt with $60 \mathrm{~mm}$ overlay. c $20 \mathrm{~mm}$ SAMI A with $60 \mathrm{~mm}$ overlay. d $20 \mathrm{~mm}$ SAMI B with $60 \mathrm{~mm}$ overlay 
overlay are greater than those for the specimens without SAMI in most cases. The contour plots of the longitudinal stresses for the control specimen with 80 -mm-thick overlay, $20 \mathrm{~mm}$ sand asphalt and $60 \mathrm{~mm}$ overlay, $20 \mathrm{~mm}$ proprietary SAMIs A and B and $60 \mathrm{~mm}$ overlay with the load placed at the centre directly above the crack top are shown in Fig. 8. The potential of SAMIs to relieve stress in the overlay can be seen in the contour plots.

\section{Discussion}

This study aims to give understanding of the performance of SAMIs using finite element analysis. It has to be said that the conditions adopted for the modelling such as assuming linear elastic behaviour for all the materials, full bonding condition and non consideration of fracture mechanics are far from reality in a typical overlaid cracked pavement incorporating SAMIs. However, previous studies have shown that the linear model could give reasonable approximation of pavement responses.

The finite element analysis shows that when SAMIs were used, greater displacements were predicted. Also, models with greater SAMIs' thickness had greater displacements. This is expected in a real pavement, as introduction of SAMIs affects the bending stiffness of the pavement. Ordinarily, it is expected that in a normal pavement, the more the displacement (deflection), the less the life of such pavement. However, in this case, researchers have shown that greater deflection recorded does not necessarily imply lesser life. Ogundipe et al. [15] and Elseifi [16] showed in their study that despite the greater deflection recorded in specimens with SAMIs, they withstood more wheel load repetitions (more life) before failure compared to those without SAMIs.

It was also found from the models results that greater strain concentration occurs around the crack region in the specimen with SAMIs than those without SAMI. Debondt [17] stated that the strain concentration occurred because of the movement of the underlying cracked pavement. Also, this could be because of the low stiffness of the SAMI, which allows it to flex (vertically or horizontal) in response to the movement of the different sides of the cracked pavement. This phenomenon also contributes to the increase in the deflection and in turns the strain concentration around the crack region.

However, the strains/stresses predicted in the overlay were less than those without SAMIs. This implies that the SAMIs somehow reduce the strain transferred to the overlay as a result of the movement of the underlying cracked layer. The introduction of the SAMIs that flex in response to the movement of the underlying layers dissipates the energy that would have been transferred to the overlay.

The strains predicted around the crack region in the models with sand asphalt were in compression, whilst it was found that the stresses/strains in the overlay were mostly greater that those predicted in the control. This is thought to be because of the very low stiffness of the SAMI and the poor fatigue properties (not reported here). This raises question about the stiffness value that is acceptable for mixtures to be used as SAMIs.

Ogundipe [18] found in his wheel tracking test that the same sand asphalt reported here was mostly ineffective in retarding crack growth. Lastly, the finite element results showed that deflection, strains and stresses predicted increases with increasing temperature.

\section{Conclusions}

The results show that when SAMIs are introduced in cracked pavements to retard reflective cracking, greater deflection of the pavement occurs. This is due to the reduced bending stiffness of the pavement caused by the introduction of SAMIs of lower stiffness than the overlay between the overlay and the existing pavement. Also, the finite element analysis shows that the models with greater SAMI thickness have greater deflection. Again, it was found that when SAMIs are introduced, greater strain concentration exists around the crack region; however, they are able to isolate the overlay from the strain concentration.

Lastly, the finite element analysis shows that although SAMIs are required to have low stiffness, a very low stiffness may give undesirable results. As, it was observed in this study, the sand asphalt having stiffness of 118,209 and $635 \mathrm{MPa}$ at 10,20 and $30{ }^{\circ} \mathrm{C}$ resulted in increased strain in the overlay.

Open Access This article is distributed under the terms of the Creative Commons Attribution License which permits any use, distribution, and reproduction in any medium, provided the original author(s) and the source are credited.

\section{References}

1. Cleveland GS, Button JW, Lytton RL (2002) Geosynthetic in flexible and rigid pavement overlay. Texas Transport Institute, Texas A\&M University System. Report 1777-1

2. Palacios C, Chehab GR, Chaignon F, Thompson M (2008) Evaluation of fibre reinforced bituminous interlayers for pavement preservation. Proceedings of 6th international RILEM conference, Chicago, 721-729

3. Kim J, Buttlar WG (2002) Analysis of reflective crack control system involving reinforcing grid over base-isolating interlayer mixture. J Transp Eng 128:375-384. doi:10.1061/(ASCE)0733947X(2002)128:4(375) 
4. Abaqus Theory Manual (2007) Dassault Systemes, Waltham

5. Sousa J, Pais J, Saim R, Way G, Stubstad R, Development of a mechanistic overlay design method based on reflective cracking concepts. Final report for Rubber Pavements Association, Consulpav International

6. Nesnas, Nunn (2004) A model for top-down reflection cracking in composite pavements. Proceedings of 5th international RILEM conference, Limoges

7. Portillo MM (2008) Measured and theoretical response of perpetual pavement structures. MSc Thesis, University of Texas, Arlington

8. Bekheet W, Hassan Y, Abd El Halim AO (2001) Modelling in situ shear strength testing of asphalt concrete pavements using finite element method. Can J Civ Eng 28:541-544

9. Wu RZ, Harvey JT (2008) Evaluation of reflective cracking performance of asphalt mixes with asphalt rubber binder using HVS tests and non-local continuum damage mechanics. Proceedings of 6th international RILEM conference, Chicago, 3-12

10. Minhoto MJC, Pais JC, Pereira PAA (2008) Reflective cracking behaviour for traffic and temperature effects. Proceedings of 6th international RILEM conference, Chicago, 551-561

11. Pais JC, Pereira PAA (2000) Predictions of existing reflective cracking potential of flexible pavements. Proceedings of 4th international RILEM conference, Ontario, 155-164

12. Dave EV, Braham AF, Buttlar WG, Paulino GH, Zofka A (2008) Integration of laboratory testing, field performance data and numerical simulations for the study of low-temperature cracking. Proceedings of 6th international RILEM conference, Chicago, 369-378

13. Baek J, Al-Qadi (2008) Mechanism of overlay reinforcement to retard reflective cracking under vehicular loading. Proceedings of 6th international RILEM conference, Chicago, 563-573

14. BSI (1993) Method for determination of the indirect tensile stiffness modulus of bituminous mixture. British Standard Institution, London (DD 213:1993)

15. Ogundipe OM, Thom N, Collop A (2013) Investigation of crack resistance potential of stress absorbing membrane interlayers (SAMIs) under traffic loading. Construction and building materials, vol 38. Elseveir, Amsterdam, pp 658-666

16. Elseifi MA (2003) Performance quantification of interlayer systems in flexible pavements using finite element analysis, instrument response and non destructive testing. PhD Thesis, Virginia Polytechnic Institute, State University

17. A.H. Debondt (1999) Anti reflective cracking design of (reinforced) asphaltic overlays. PhD Thesis, Delft University of Technology, Netherlands

18. Ogundipe OM (2011) Mechanical behaviour of stress absorbing membrane interlayers. PhD Thesis, University of Nottingham, Nottingham 